\title{
NON-UNIFORM PULMONARY DIFFUSION AS DEMONSTRATED BY THE CARBON MONOXIDE EQUILIBRATION TECHNIQUE: MATHEMATICAL CONSIDERATIONS*
}

\author{
By Benjamin Burrows, Albert H. Niden, Paul V. Harper, Jr. and William R. Barclay
}

(From the Departments of Medicine and Surgery, University of Chicago, Chicago, Ill.)

(Submitted for publication December 9, 1959; accepted January 15, 1960)

It is now well established that both ventilation and perfusion are distributed unevenly throughout the lung. Inert gas washout curves have consistently revealed non-uniformity of ventilation/lung volume $\left(\dot{\mathrm{V}}_{\mathrm{A}} / \mathrm{V}_{\mathrm{A}}\right)$ ratios $(1-3)$; study of the respiratory exchange ratios in different parts of the lung has provided evidence of uneven ventilation/perfusion $\left(\dot{V}_{\mathrm{A}} / \dot{Q}_{\mathrm{C}}\right)$ ratios $(4,5)$, and both bronchospirometric studies (6) and measurements of physiological dead space (7) have supported these findings. ${ }^{1}$ Analysis of single

* This research was supported by a grant from the Illinois Tuberculosis Association.

${ }^{1}$ Definitions of symbols:

DL $=$ pulmonary diffusing capacity

$\mathrm{VA}_{\mathrm{A}}=$ alveolar volume

$\dot{V}_{\mathrm{A}}=$ alveolar ventilation per unit time

$\dot{Q} \mathrm{c}=$ pulmonary capillary blood flow

$\mathrm{VTA}=$ alveolar tidal volume

VFRC $=$ end expiratory alveolar volume

$\mathrm{Vc}=$ blood volume of the pulmonary capillary bed

DM = true diffusing capacity of the pulmonary membrane

$\mathrm{t}=$ any time interval

tb $=$ time for a single breath cycle

$\mathrm{f}=$ respiratory frequency $(\mathrm{f}=1 / \mathrm{tb})$

$\mathrm{PB}_{\mathrm{B}}=$ barometric pressure corrected for water vapor

$\mathrm{Y}$ and $\mathrm{Z}=$ symbols for compartments of the lung, applied as subscripts (e.g., $\mathrm{VAz}_{\mathrm{z}}$ and so forth)

$\mathrm{FAX}_{\mathrm{AX}}=$ fractional concentration of any gas $\mathrm{X}$ in alveolar gas

$F_{I X}=$ fractional concentration of any gas $X$ in inspired gas

$\operatorname{FET}_{X}=$ fractional concentration of any gas $\mathrm{X}$ in end tidal gas

FEIX $=$ fractional concentration of any gas $\mathrm{X}$ in alveolar gas at the end of inspiration

$F \dot{V}_{Y}=$ fraction of $\dot{V}_{A}$ to compartment $Y$

$\mathrm{F} \dot{V}_{z}=$ fraction of $\dot{V}_{A}$ to compartment $Z$

$\mathrm{K}_{\mathrm{N}_{2}}=\mathrm{a}$ constant indicative of the rate of inert gas washout

$\mathrm{Kco}=\mathrm{a}$ constant indicative of the total rate of carbon monoxide disappearance from alveolar gas due to diffusion plus ventilation

$\mathrm{KD}=\mathrm{a}$ constant indicative of the rate of carbon monoxide disappearance from alveolar gas due to diffusion alone $\left(\mathrm{KD}=\mathrm{PBDL}_{\mathrm{L}} / \mathrm{VA}_{\mathrm{A}}\right)$ expirates has indicated, in addition to $\dot{V}_{A} / \dot{Q}_{C}$ inequality, non-uniformity of perfusion/lung volume ratios (Q்/VA) throughout the lung $(8,9)$. Results with differential bronchiospirometry indicate a definite $\dot{Q} \mathrm{c} / \mathrm{V}_{\mathrm{A}}$ difference between the two lungs when the subject lies on his side (10). Available evidence suggests that perfusion is reduced in the superior portions of lung due to hydrostatic effects (11), accounting for an increased unevenness of $\dot{\mathrm{V}} \mathrm{A} / \dot{\mathrm{Q}} \mathrm{c}$ in the erect posture as compared with the supine (7) and explaining the low oxygen uptake and low QC/VA ratio of the uppermost portions of the lung $(6,10,12)$. One would expect diffusion across the alveolar-capillary membrane in a given volume of lung to be related to the effective capillary bed in that region, and variation in $\dot{Q} \mathrm{c} / \mathrm{V}_{\mathrm{A}}$ to be reflected in variations of the ratio of diffusing capacity to lung volume (DL/VA).

Direct evidence of DL/VA non-uniformity was first reported by Forster, Fowler, Bates and Van Lingen (13). These investigators noted that the disappearance of carbon monoxide from alveolar gas during breath holding did not follow a simple exponential curve as theoretically expected; the effect was explained by non-uniform $D_{L} / V_{A}$ ratios in the lung, those areas with low diffusion causing an apparent slowing of carbon monoxide disappearance when long breath holding times were utilized. The findings of Forster and co-workers have been confirmed by others $(14,15)$ although at least one observer has failed to note the phenomenon (16). Unfortunately, the breath holding method is not suitable for quantification of non-uniformity of DL/VA; with this method, overall DL is esti-

$\mathrm{W}=$ the dilution factor for a uniform lung during washout, such as $\mathrm{W}=\mathrm{VFRC} /(\mathrm{VFRC}+\mathrm{VTA})$

Subscript $t=$ at time $t$

Subscript $\mathbf{0}=$ at onset of time interval $t$

Subscript $\infty=$ after complete equilibration with an inhaled gas. 
mated by using an arbitrary period of breath holding and assuming uniform diffusion. Thus, calculated DL varies with the period of breath holding utilized. Other methods for determining the pulmonary diffusing capacity [e.g., the steady state carbon monoxide method of Filley, MacIntosh and Wright (17) and the oxygen method of Riley and Cournand (18)] do not directly reflect variability in DL/VA but may yield erroneous values for total $\mathrm{DL}_{\mathrm{L}}$ in the presence of $\mathrm{DL} / \dot{\mathrm{V}}_{\mathrm{A}}$ or $\dot{\mathrm{V}}_{\mathrm{A}} / \dot{Q}_{\mathrm{C}}$ non-uniformity. This problem has been reviewed in some detail by Forster (19).

In 1958, a method was described in this laboratory for determining DL from carbon monoxide equilibration curves (20), a method which was similar in approach to that of Gilson and HughJones (21). With the technique originally employed, no evidence of $D_{L} / V_{A}$ variability was demonstrated in several normal individuals. However, with improved methods (including more careful control of tidal volume and breathing pattern as well as incorporation of helium as an indicator of inert gas equilibration), it is apparent that $\mathrm{DL} / \mathrm{VA}$ ratios are non-uniform in the normal subject. In addition, it has been noted that unevenness of diffusion may be increased by full inflation of the lung (15), and (as will be shown in the following paper of this series) that $\mathrm{DL} / \mathrm{VA}_{\mathrm{A}}$ variations may be marked in pathological lungs and in certain experimental preparations. The equilibration technique provides sufficient data to calculate $D_{L} / V_{A}$ variations if certain assumptions are allowed. It is the purpose of this report to describe the theoretical basis for such calculations and to outline the methods involved. In addition to assessing the degree of non-uniformity of diffusion, such methods could provide an estimate of overall DL which is free from the errors induced by nonuniformity of $\dot{\mathrm{V}}_{\mathrm{A}} / \mathrm{VA}_{\mathrm{A}}, \dot{\mathrm{Q}}_{\mathrm{C}} / \dot{\mathrm{V}}_{\mathrm{A}}$, or $\mathrm{DL} / \mathrm{VA}_{\mathrm{A}}$. In the second paper of this series, these methods of calculation are applied to obtain experimental data in man.

\section{CALCULATIONS}

Mathematical relationships in a uniform lung. It is possible to predict the changes in end tidal gas which will result in an ideal uniform lung when inhaled gas is changed from room air to a helium-carbon monoxide mixture and when this mixture is replaced by room air. The mathe- maticai relationships during carbon monoxide equilibration and washout were considered in some detail in a previous report (20). In the ideal lung there will be an exponential increase in FET $_{\mathrm{H} \in}$ following exposure to helium, and at equilibrium $\mathrm{FET}_{\mathrm{H} \epsilon_{\infty}}=\mathrm{FI}_{\mathrm{He}}$. On inspiring the carbon monoxide-helium mixture, there will be an exponential increase in end tidal carbon monoxide, but in the presence of diffusion, $\mathrm{FET}_{\mathrm{CO}_{\infty}}<\mathrm{FI}_{\mathrm{CO}}$. When room air is again inhaled, FET $_{\mathrm{CO}}$ and FET $_{\mathrm{He}}$ will decrease exponentially to baseline values.

The rate of decline of carbon monoxide must exceed that of helium since carbon monoxide disappears from the alveoli due to a combination of diffusion and simple washout, while helium disappears solely from ventilatory effects. Since both helium and carbon monoxide disappearances will follow a simple exponential function during washout, successive end tidal values of each will describe a straight line when plotted semilogarithmically against time. In this circumstance, DL may be calculated simply from obtained data if $\mathrm{VA}_{\mathrm{A}}$ is known:

and

$$
\begin{aligned}
& \mathrm{FET}_{\mathrm{He}_{\mathrm{t}}}=\mathrm{FET}_{\mathrm{He}_{\mathrm{o}}} \mathrm{e}^{-\mathrm{K}_{\mathrm{N}_{2} \mathrm{t}},} \\
& \mathrm{FET}_{\mathrm{CO}_{\mathrm{t}}}=\mathrm{FET}_{\mathrm{CO}_{\mathrm{o}}} \mathrm{e}^{-\mathrm{K}_{\mathrm{CO}}},
\end{aligned}
$$

$$
\mathrm{DL}_{\mathrm{L}}=\mathrm{VA}_{\mathrm{A}}\left(\mathrm{K}_{\mathrm{CO}}-\mathrm{KN}_{2}\right) / \mathrm{PB},
$$

Equations 1 and 2 defining the constants $\mathrm{KN}_{2}$ and Kco.

In addition, it was shown (20) that

$$
\mathrm{F}_{\mathrm{AO}_{\infty}}=\mathrm{FI}_{\mathrm{COO}_{\mathrm{O}} \mathrm{KN}_{2}} / \mathrm{KCO} \text {. }
$$

If one considers the changes in FACo during a single breath cycle after equilibration with an inspired $\mathrm{CO}$ mixture (Figure 1), it will be noted that $\mathrm{FACO}_{\mathrm{CO}_{\infty}}$ calculated from Equation 4 is an "average" value and that $\mathrm{FACO}_{\mathrm{CO}_{\infty}} \neq \mathrm{FET}_{\mathrm{CO}_{\infty}}$ unless $f=\infty$. In order to utilize the observable $\mathrm{FET}_{\mathrm{CO}_{\infty}}$ in place of $\mathrm{FACO}_{\mathrm{CO}_{\infty}}$ in Equation 4, a relationship must be derived between $\mathrm{FA}_{\mathrm{CO}_{\infty}}$ and

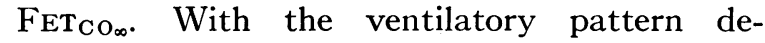
scribed in Figure 1, and when $\mathrm{FA}_{\mathrm{CO}_{\infty}}=0.5 \mathrm{FI}_{\mathrm{CO}}$,

$$
\mathrm{FACO}_{\infty}=\left(\mathrm{FEI}_{\mathrm{CO}_{\infty}}+\mathrm{FET}_{\mathrm{CO}_{\infty}}\right) / 2 \text {. }
$$

Equation 5 is strictly true only when $\mathrm{FACO}_{\mathrm{CO}_{\infty}}$ $=0.5 \mathrm{FI}_{\mathrm{CO}}$, because only then will the $\mathrm{F}_{\mathrm{ACO}}$ curves during inspiration and expiration be mirror images of one another. Since there is no change in FACO due to ventilation in the ex- 


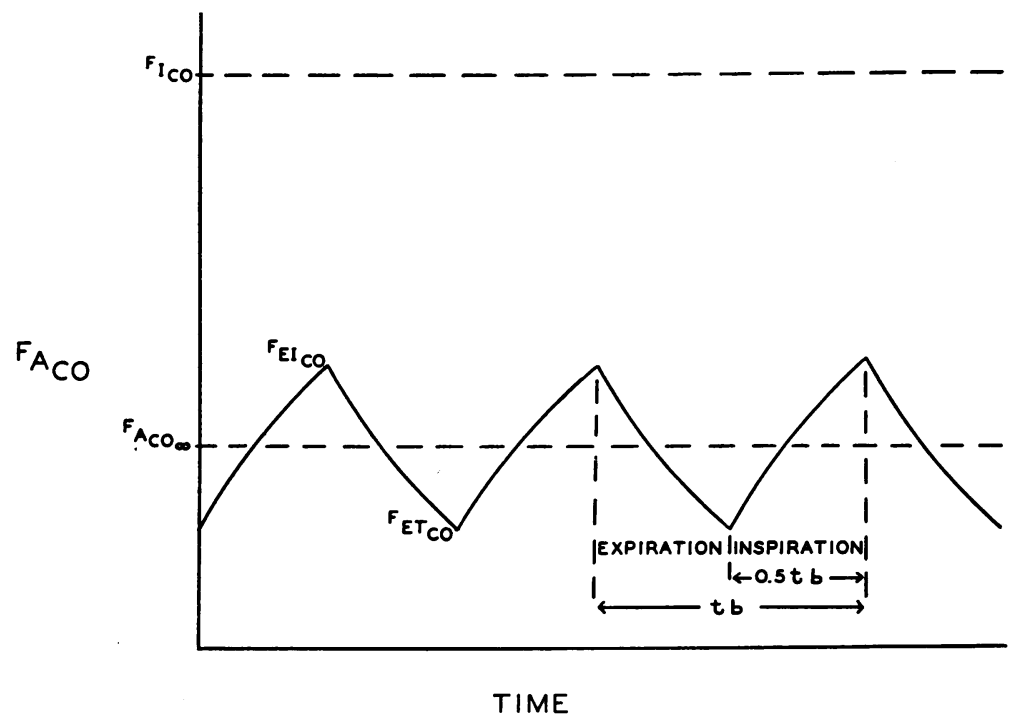

Fig. 1. Changes in the concentration of Carbon monoxide in ALVEOLAR GAS (FACO) AFTER EQUILIBRATION WITH AN INSPIRED CO MIXTURE DURING THE BREATHING CYCLE. It is assumed that inspiration proceeds at such a rate that there is an exponential increase in $\mathrm{FACO}_{\mathrm{Aco}}$ during the inspiratory period (i.e., during inspiration, $\mathrm{dF}_{\mathrm{A}_{\mathrm{CO}}}=\mathrm{dtK}\left(\mathrm{F}_{\mathrm{I}_{\mathrm{CO}}}-\mathrm{F}_{\mathrm{ACO}_{\mathrm{CO}}}\right)$. The peak value of $\mathrm{FACO}_{\mathrm{ACO}}$ will be reached at the end of inspiration $\left(\mathrm{FEICO}_{\infty}\right)$. During expiration, loss of carbon monoxide due to diffusion results in a decreasing $\mathrm{FACO}_{\mathrm{ACO}}$, reaching its lowest value at end expiration $\left(\mathrm{FET}_{\mathrm{CO}_{\infty}}\right)$. Inspiration and expiration are assumed to be equal in duration.

piratory phase, by Krogh's formula (22),

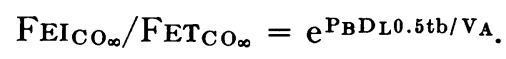

Since

$$
\begin{aligned}
& \mathrm{KD}=\mathrm{PBDL}_{\mathrm{B}} / \mathrm{VA}_{\mathrm{A}}, \\
& \mathrm{FEI}_{\mathrm{CO}_{\infty}} / \mathrm{FET}_{\mathrm{CO}_{\infty}}=\mathrm{e}^{\mathrm{K}_{\mathrm{D} 0.5 \mathrm{tb}}} .
\end{aligned}
$$

Combining this last equation with Equation 5,

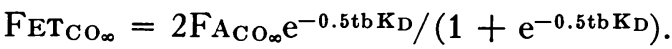

When $\mathrm{FACO}_{\mathrm{CO}_{\infty}} \neq 0.5 \mathrm{FI}_{\mathrm{CO}}$, the estimate of $\mathrm{FACO}_{\mathrm{CO}_{\infty}}$ in Equation 5 is inexact, and this error is reflected in Equation 6. However, the final error is small unless $\mathrm{F}_{\mathrm{AO}_{\infty}}$ approaches either zero or $\mathrm{FI}_{\mathrm{CO}}$; this is unlikely to occur with physiological parameters for $\mathrm{KN}_{2}$ and $\mathrm{KcO}$.

Since it has been shown (20) that $\mathrm{KD}=\mathrm{KCO}$ - $\mathrm{KN}_{2}$, it is now possible to approximate $\mathrm{FET}_{\mathrm{CO}}$ from Equations 4 and 6 if these $K$ values are known. These relationships will be necessary in the calculation of a two-compartment system to be discussed.

Mathematical relationships in a two-compartment lung. When successive end tidal values for an inert insoluble gas during washout fail to define a straight line when plotted similogarithmically against time, variability of $\dot{V}_{A} / V_{A}$ is indi- cated. If such data are suitable for analysis in terms of a two-compartment system,

$$
\begin{aligned}
& \mathrm{FET}_{\mathrm{He}_{\mathrm{t}}}=\mathrm{F} \dot{\mathrm{V}}_{\mathrm{Y}} \mathrm{FET}_{\mathrm{He}_{\mathrm{O}} \mathrm{Y}} \mathrm{e}^{-\mathrm{K}_{\mathrm{N}_{2} \mathbf{Y}} \mathrm{t}} \\
& +F \dot{V}_{Z} F_{E T}{ }_{H_{O} Z} e^{-K_{N_{2}}{ }^{t}} \text {. } \\
& \mathrm{FET}_{\mathrm{He}_{\mathrm{O}} \mathrm{Y}}=\mathrm{FET}_{\mathrm{He}_{\mathrm{OZ}}}=\mathrm{FET}_{\mathrm{He}_{\mathrm{O}}} \text {, }
\end{aligned}
$$

obtainable data define all values in Equation 7, and, by graphic analysis, values for $F \dot{V}_{Y}, K_{2_{Y}}$, $F \dot{V}_{z}$, and $K_{N_{2}}$ may be determined. Also, the slope of the washout points determines $\mathrm{Wy}$ and $\mathrm{Wz}$ (see analysis of experimental data). Since total VFRC may be determined independently, it is now possible to calculate $V_{F R C y}, V_{F R C Z}$, VTAY, and VTAZ by modification of the methods of Fowler, Cornish and Kety (2):

$$
\begin{aligned}
& \mathrm{VFRC}_{\mathrm{Y}} / \mathrm{VFRC}_{\mathrm{Z}}=\mathrm{F} \dot{\mathrm{V}}_{\mathrm{Y}} \mathrm{WY}(\mathrm{I}-\mathrm{Wz}) / \\
& \mathrm{F} \dot{\mathrm{V}}_{\mathrm{z}} \mathrm{Wz}(\mathrm{I}-\mathrm{Wy}) \text {, } \\
& \mathrm{VFRC}_{Z}=\frac{\mathrm{VFRC}_{\mathrm{Z}}}{\left(\mathrm{VFRC}_{\mathrm{Y}} / \mathrm{VFRC}_{\mathbf{Z}}\right)+1}, \\
& \mathrm{VFRC}_{\mathrm{Y}}=\mathrm{VFRC}-\mathrm{VFRC}_{\mathrm{Z}}, \\
& \operatorname{VTAY}_{\mathrm{Y}}=\operatorname{VFRCY}_{\mathrm{Y}}(1-\mathrm{WY}) / \mathrm{WY}, \\
& \operatorname{VTAz}_{\mathrm{Z}}=\operatorname{VFRC}_{\mathrm{Z}}(\mathrm{I}-\mathrm{Wz}) / \mathrm{Wz} .
\end{aligned}
$$




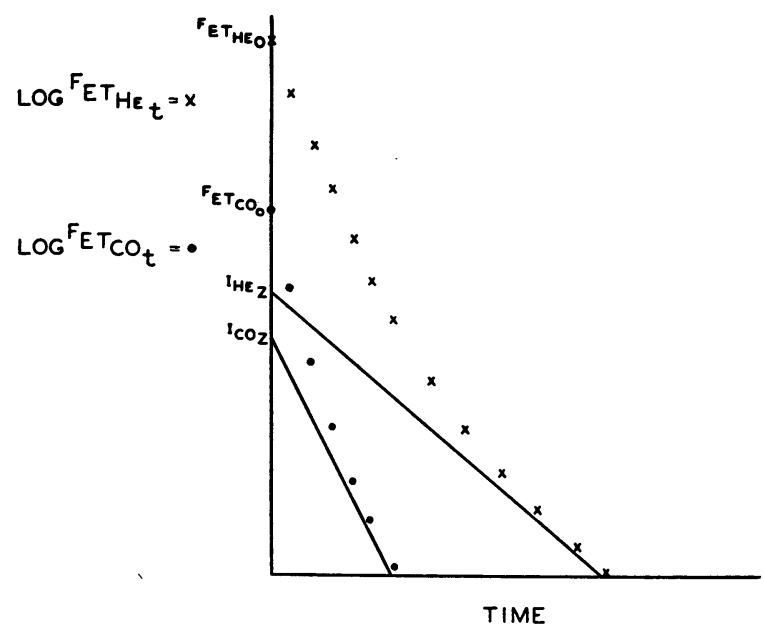

Fig. 2. HyPOTHETICAL END TIDAL CARBON MONOXIDE AND HELIUM CONCENTRATIONS AS MIGHT BE OBTAINED IN THE WASHOUT PERIOD OF AN EQUILIBRATION TEST, PLOTTED SEMILOGARITHMICALly AGAINST TIME. The oblique solid lines represent tangents to the terminal portions of the curves determined by these successive helium and carbon monoxide values. See text for further explanation.

As discussed in a previous report (20), VA may be approximated as VFRC + VTA/2, allowing calculation of $\mathrm{VAY}_{\mathbf{Y}}$ and $\mathrm{VAZ}_{\mathbf{Z}}$ from the above parameters :

$$
\begin{aligned}
& \mathrm{VAY}_{\mathrm{Y}}=\mathrm{VFRC}_{\mathrm{Y}}+\mathrm{VTA}_{\mathrm{Y}} / 2, \\
& \mathrm{VA}_{\mathrm{Z}}=\mathrm{VFRC}_{\mathrm{Z}}+\mathrm{VTA}_{\mathrm{Z}} / 2 .
\end{aligned}
$$

Successive end tidal carbon monoxide values will fail to define a straight line on semilogarithmic plot if Kco's are non-uniform throughout the lung. Since $\mathrm{KCO}=\mathrm{KN}_{2}+\mathrm{KD}$, this could be due to non-uniformity of $\mathrm{KN}_{2}, \mathrm{KD}$, or both.' Since $\mathrm{KD}=\mathrm{PBDL}_{\mathrm{B}} / \mathrm{VA}_{\mathrm{A}}$, non-uniformity of $\mathrm{KD}$ implies unevenness of $\mathrm{DL} / \mathrm{VA}_{\mathrm{A}}$ ratios. If data may be expressed in terms of two compartments, $\mathrm{Y}$ and $Z, \mathrm{FET}_{\mathrm{CO}_{t}}$ will follow a modification of Equation 2:

$$
\begin{aligned}
& \text { FET }_{\mathrm{CO}_{t}}=\mathrm{FV}_{\mathrm{Y}} \mathrm{FET}_{\mathrm{CO}_{O \mathrm{Y}}} \mathrm{e}^{-\mathrm{K}_{\mathrm{CO}} \mathrm{Y}_{\mathrm{Y}} \mathrm{t}} \\
& +\mathrm{Fv}_{\mathrm{z}} \mathrm{FET}_{\mathrm{CO}_{\mathrm{o}} \mathrm{z}} \mathrm{e}^{-\mathrm{K}_{\mathrm{CO}} \mathrm{t}} \text {. }
\end{aligned}
$$

Obtained carbon monoxide washout curves will not provide a unique solution to this above equation since FET $_{\mathrm{CO}_{\mathrm{O}_{\mathrm{Y}}}} \neq \mathrm{FET}_{\mathrm{CO}_{\mathrm{OZ}}} \neq \mathrm{FET}_{\mathrm{CO}_{0}}$. In this important respect, there is considerable difference in the complexity of Equations 7 and 15. Since $\mathrm{KCO}_{\mathrm{y}}$ and $\mathrm{KCO}_{\mathrm{z}}$ cannot be determined directly from Equation 15, it will be necessary to utilize the additional relationships in each compartment at time $\infty$. To this end, Equations 4 and 6 may be rewritten to apply to the individual compartments $\mathrm{Y}$ and $\mathrm{Z}$. Also,

$$
\mathrm{FET}_{\mathrm{CO}_{\infty}}=\mathrm{Fv}_{\mathbf{Y}} \mathrm{FET}_{\mathrm{CO}_{\infty} \mathbf{Y}}+\mathrm{Fv}_{\mathbf{Z}} \mathrm{FET}_{\mathrm{CO}_{\infty} \mathrm{Z}} \text {. }
$$

When applied simultaneously to obtained data, the relationships in Equations 4, 6, 15 and 16 allow a solution of the diffusing characteristics of $\mathrm{Y}$ and $\mathrm{Z}$ if certain assumptions are utilized.

Analysis of experimental data in terms of a twocompartment model. It will be assumed that the lung may be defined in terms of a simple model with a specific number of ventilatory and diffusing compartments and that these compartments may be related to each other in some predetermined manner. In order to minimize calculated variations in $\mathrm{DL}_{\mathrm{L}} / \mathrm{VA}_{\mathrm{A}}$, those alveoli with the slowest ventilation (lowest $\mathrm{KN}_{2}$ ) are assumed also to have the slowest ventilation plus diffusion (lowest Kco). This implies that the slowest portions of both helium and carbon. monoxide washout curves arise from the same alveoli.

Consider an equilibration test yielding the data in Figure 2. Successive end tidal helium values fail to define a straight line when plotted logarithmically against time, indicating variable $\dot{\mathrm{V}}_{\mathrm{A}} / \mathrm{V}_{\mathrm{A}}$ ratios. In a two-compartment lung, the lower $\dot{V}_{A} / V_{A}$ ratio (Compartment $Z$ ) will be reflected in the slope of the terminal portion of the helium curve. A tangent to this portion of the curve has a slope equal to $\log \mathrm{Wz} . \quad \mathrm{KN}_{2 \mathrm{Z}}$ may be determined from two points on the tangent as follows:

$$
\mathrm{KN}_{\mathbf{2}_{\mathbf{Z}}}=\ln \left(\mathrm{FET}_{\mathrm{He}_{\mathrm{O}}} / \mathrm{FET}_{\mathrm{He}_{\mathrm{t}}}\right) / \mathrm{t} \text {. }
$$

The intercept of the inscribed tangent at zero time $\left(\mathrm{IHe}_{\mathrm{z}}\right.$ ) will determine $\mathrm{Fv}_{\mathbf{z}}$ :

$$
\mathrm{Fv}_{\mathrm{Z}}=\mathrm{IHe}_{\mathrm{Z}} / \mathrm{FET}_{\mathrm{He}_{\mathrm{o}}} \text {. }
$$

Subtracting the inscribed tangent from successive end tidal helium values allows one to draw a line for Compartment $Y$; its slope represents $\log \mathrm{Wy}$. From this slope, $\mathrm{KN}_{\mathbf{2}}$ may be determined:

$$
\mathrm{KN}_{\mathbf{2}_{\mathbf{Y}}}=\ln \left(\mathrm{FET}_{\mathrm{H}_{\mathrm{O} \mathbf{Y}}} / \mathrm{FET}_{\mathrm{He}_{\mathrm{tY}}}\right) / \mathrm{t} \text {. }
$$

$\mathrm{FV}_{\mathbf{Y}}$ equals $\mathrm{I}-\mathrm{Fv}_{\mathrm{Z}}$ in a two-compartment lung. If VFRC is known, the values for $F \dot{V}_{Y}, F \dot{V}_{Z}, W y$, and $W z$ may be utilized in Equations 8 through 12 to determine VFRC,$V_{Y}$, VRC $_{Z}$, Vtay, and Vtaz. 
Then, $\mathrm{VAY}_{\mathrm{Y}}$ and $\mathrm{VA}_{\mathrm{Z}}$ are calculated from Equations 13 and 14.

Now consider the carbon monoxide curve in Figure 2. Using the lung model defined, the terminal slope of this curve must represent the washout plus diffusion in Compartment $Z$. If the lung model described is applicable and contains only two compartments, it must be possible to inscribe a tangent to the terminal slope of the carbon monoxide washout curve which will yield a value for $F \dot{v}_{z}$ identical with that determined from helium data in Equation 17. The slope of such a tangent would determine $\mathrm{KCO}_{\mathrm{z}}$ :

$$
\mathrm{KCO}_{\mathrm{Z}}=\ln \left(\mathrm{FET}_{\mathrm{CO}_{\mathrm{oz}}} / \mathrm{FET}_{\mathrm{CO}_{\mathrm{tz}}}\right) / \mathrm{t},
$$

and

$$
\mathrm{KD}_{\mathrm{Z}}=\mathrm{KCO}_{\mathrm{z}}-\mathrm{KN}_{\mathbf{2}_{\mathbf{z}}} \text {. }
$$

Since the carbon monoxide in Compartment $\mathrm{Y}$ approximates zero by the time the final end tidal $\mathrm{CO}$ values are obtained, the intercept of the above described tangent at zero time $\left(\mathrm{ICO}_{\mathrm{z}}\right)$ would determine $\mathrm{F}_{\mathbf{z}}$, if $\mathrm{FET}_{\mathrm{CO}_{\mathrm{o}}}$ were known. FET $_{\mathrm{CO}_{\text {oz }}}$ does not equal observed $\mathrm{FET}_{\mathrm{CO}_{0}}$, but may be calculated by applying values for $\mathrm{KN}_{2_{Z}}$, $\mathrm{KD}_{\mathrm{z}}$, and $\mathrm{KCO}_{\mathrm{z}}$ to Equations 4 and $6 . \mathrm{FET}_{\mathrm{CO}_{\infty}}$ from these equations is equal to $\mathrm{FET}_{\mathrm{CO}_{\mathrm{OZ}}}$ for the carbon monoxide washout period. Having determined $\mathrm{FET}_{\mathrm{CO}_{\mathrm{oZ}}}$,

$$
\mathrm{F}_{\mathrm{Z}}=\mathrm{ICO}_{\mathrm{Z}} / \mathrm{FET}_{\mathrm{CO}_{\mathrm{O}}} .
$$

If the values for $F \dot{V}_{z}$ from Equations 17 and 18 do not agree, it may be possible to adjust the tangent to the terminal carbon monoxide points until agreement is reached. The ability to inscribe a satisfactory tangent is a test of the suitability of a two-compartment lung model. When agreement in $\mathrm{F}_{\mathrm{V}} \mathrm{z}$ has been achieved, the value of $\mathrm{FET}_{\mathrm{CO}_{\mathrm{O}} \mathrm{z}}$ may be utilized in determining the parameters of Compartment $\mathrm{Y}$ as follows:

$$
\mathrm{FET}_{\mathrm{CO}_{O_{\mathbf{Y}}}}=\left(\mathrm{FET}_{\mathrm{CO}_{\mathrm{O}}}-\mathrm{F}_{\mathrm{Z}} \mathrm{FET}_{\mathrm{CO}_{O_{\mathrm{Z}}}}\right) / \mathrm{F} \dot{\mathrm{V}}_{\mathrm{Y}} .
$$

Substituting $\mathrm{FET}_{\mathrm{CO}_{\mathrm{OY}}}$ and $\mathrm{KN}_{\mathbf{2}}$ in Equations 4 and 6 allows calculation of $\mathrm{KCO}_{\mathrm{Y}}$ and $\mathrm{KDy}$.

Now,

and

$$
\begin{aligned}
& \mathrm{D}_{\mathrm{Y}}=\mathrm{K}_{\mathrm{D}_{\mathrm{Y}} \mathrm{V}_{\mathrm{AY}} / \mathrm{PB}_{\mathrm{B}},} \\
& \mathrm{D}_{\mathrm{L}_{\mathrm{Z}}}=\mathrm{K}_{\mathrm{D}_{\mathrm{Z}} \mathrm{V}_{\mathrm{A}_{\mathrm{Z}}} / \mathrm{PB}_{\mathrm{B}},}
\end{aligned}
$$

$$
D_{L}=D_{L_{Y}}+D_{L} .
$$

Since values for Compartment $\mathrm{Y}$ were determined entirely from relationships at time $\infty$, it is still necessary to demonstrate that these parameters satisfactorily explain the end tidal carbon monoxide values during washout. To this end, obtained values for both compartments are applied to Equation 15, and the theoretical carbon monoxide disappearance curves for Compartments $\mathrm{Y}+Z$ are compared with obtained end tidal points. Agreement confirms the suitability of the model utilized and serves as a check on calculations.

If a satisfactory solution cannot be obtained in terms of two compartments, a new model must be utilized in which three or more compartments are calculated. The methods are identical to those described above, the contributions of the additional compartments being subtracted serially from observed data.

\section{DISCUSSION}

In the method outlined, an attempt is made to analyze data obtained during equilibration and disequilibration with a carbon monoxide mixture in terms of a compartmented lung. It has been found necessary to utilize an arbitrary lung model, the suitability of which must be proven by its applicability to data obtained. Such a model does not pretend to reflect actual anatomic divisions of the lung. However, the description of non-uniform events in terms of simple compartments has been widely utilized, and the compartment concept greatly simplifies calculations.

It has been necessary to assume a relationship between ventilatory and diffusing compartments in order to keep the number of compartments at a minimum. There is experimental evidence that DL/VA ratios are similar in portions of the lung which vary in $\dot{\mathrm{V}}_{\mathrm{A}} / \mathrm{V}_{\mathrm{A}}$, at least as $\dot{\mathrm{V}}_{\mathrm{A}} / \mathrm{V}_{\mathrm{A}}$ variations are reflected in various portions of expired gas (23). Despite this report, it is difficult to believe that $D_{L} / V_{A}$ ratios bear no relation whatever to ventilatory characteristics, at least in pathological lungs (e.g., lung cysts). In any event, applying non-uniform $\mathrm{DL} / \mathrm{VA}_{\mathrm{A}}$ ratios to each ventilatory compartment would create a minimum of four compartments. In addition, such a model would tend to exaggerate DL/VA unevenness in certain situations. By assuming that slowly ventilated areas have a 
slow sum of ventilation plus diffusion, one minimizes calculated variations in DL/VA and allows the determination of uniform diffusion in the face of $\dot{V}_{A} / V_{A}$ variability. It would be impossible to assume identity of a fast ventilating region $(Y)$ with one having slow ventilation plus diffusion $(Z)$ since, in some sets of data, $\mathrm{KN}_{\mathrm{2}_{\mathrm{Y}}}$ exceeds $\mathrm{KCO}_{\mathrm{z}}$. Support for the approach used may be found in the observations of West, Fowler, Hugh-Jones and O'Donnell (9) who noted that poorly ventilated alveoli appear to be poorly perfused.

An assumption has been utilized in derivation of Equation 6; this formula is based on a breathing pattern in which inspiration and expiration are equal in time and in which inspiration proceeds at such a rate that there is an exponential increase in $F_{A_{\mathrm{CO}}}$ during the inspiratory period. Any other breathing pattern could have been utilized as a basis for calculation, but the one employed is simple and closely resembles physiological conditions. The error involved in minor deviations from this pattern is small.

In the method described, there is the tacit assumption that end tidal samples are representative of the alveolar pool at that point in time. When there is uniformity of the expired gas throughout the expiratory period, this assumption is valid, and this situation is approached for an inert gas in a normal subject. With an abnormal lung, one will tend to overestimate the size of the slowly ventilated areas by end tidal samples, since such areas tend to empty relatively late in expiration. Ogilvie, Forster, Blakemore and Morton have been unable to relate diffusion measurements to the portion of expirate examined (23); if this is the case, diffusion measurements in end tidal samples should be valid for the lung as a whole. However, the sizes of the various compartments might still be in error in the abnormal lung since these dimensions are dependent upon inert gas measurements. Besides, it is difficult to believe that Forster's observations of equal diffusion in all portions of the expirate would apply universally. The errors involved in end tidal sampling could be circumvented by analysis of mixed single expirates; as yet, this is not technically feasible.

It should also be emphasized that the analytical methods described herein are crude and time consuming, consisting of a trial and error graphic fit. It seems likely that refinements in technique of calculation are possible, especially by incorporation of electronic computation. This might allow the utilization of a more complex lung model which would more closely resemble physiological parameters.

The method described is subject to all the assumptions and errors of carbon monoxide techniques in general. During the early phases of carbon monoxide disappearance, the problems are similar to those of the breath holding method; these have been discussed in detail by Forster and co-workers (13). As one approaches the terminal portion of the carbon monoxide disappearance curve, the problem of back pressure becomes more important. Ideally, one would account for the value of the back pressure of carbon monoxide in formulation of diffusion effects, but this would add considerably to the complexity of calculations. As the procedure is currently employed, the final FET Co $_{\text {ochieved after several }}$ minutes of air breathing is utilized as a baseline for $\mathrm{FET}_{\mathrm{CO}_{\mathrm{t}}}$ during washout and, as such, represents an estimate of $\mathrm{CO}$ back pressure. This value for FET $_{\mathrm{CO}}$ is a result of two opposing phenomena - the back diffusion of carbon monoxide from blood to alveolus and the ventilation of carbon monoxide from alveolus to atmosphere. The final value of $\mathrm{FET}_{\mathrm{CO}}$ will lie somewhere between the carbon monoxide in room air and the tension of carbon monoxide in the pulmonary capillary blood. Due to this inaccuracy in estimation of true back pressure, some error in calculated Kco must result. With normal parameters, and with low concentration of carbon monoxide in inhaled gas, this error is relatively small.

Despite the various limitations outlined, the ability to estimate total pulmonary diffusing capacity in the face of variable $\mathrm{DL} / \mathrm{VA}_{\mathrm{A}}$ ratios would seem of sufficient importance to warrant a trial of the technique, even if quantitative technics are imperfect. In a following paper these methods are applied to data obtained in human subjects. Animal experiments are also reported which indicate the validity and applicability of the procedure.

\section{SUMMARY}

1. A method has been described for calculating compartments with varying diffusing character- 
istics (i.e.,; non-uniform diffusing capacity to lung volume ratios) from carbon monoxide equilibration curves. By adding the diffusing capacities calculated for each compartment, a total diffusing capacity may be determined which is theoretically free of the errors induced in conventional diffusion techniques by non-uniformity of pulmonary diffusion.

2. The methods described require the utilization of an arbitrary lung model. The applicability of this model must be demonstrated by its ability to explain experimental results.

3. In the following paper, these methods will be applied to experimental data, and further implications of diffusing capacity per lung volume non-uniformity will be discussed.

\section{ACKNOWLEDGMENT}

The authors are indebted to Dr. W. S. Fowler of the Mayo Clinic for his suggestions and criticisms.

\section{REFERENCES}

1. Robertson, J. S., Siri, W. E., and Jones, H. B. Lung ventilation patterns determined by analysis of nitrogen elimination rates; use of the mass spectrometer as a continuous gas analyzer. J. clin. Invest. 1950, 29, 577.

2. Fowler, W. S., Cornish, E. R., Jr., and Kety, S. S. Lung function studies. VIII. Analysis of alveolar ventilation by pulmonary $\mathrm{N}_{2}$ clearance curves. J. clin. Invest. 1952, 31, 40.

3. Briscoe, W. A., and Cournand, A. Uneven ventilation of normal and diseased lungs studied by an open-circuit method. J. appl. Physiol. 1959, 14, 284.

4. Martin, C. J., Cline, F., Jr., and Marshall, H. Lobar alveolar gas concentrations: Effect of body position. J. clin. Invest. 1953, 32, 617.

5. Martin, C. J., Cline, F., Jr., and Marshall, H. Lobar alveolar gas concentration after pneumonectomy. J. clin. Invest. 1955, 34, 875 .

6. Inada, K., Kishimoto, S., Sato, A., and Watanabe, T. Bronchospirometry with the Carlens double lumen catheter; evaluation of exercise test. J. thorac. Surg. 1954, 27, 173.

7. Riley, R. L., Permutt, S., Said, S., Godfrey, M., Cheng, T. O., Howell, J. B. L., and Shepard, R. H. Effect of posture on pulmonary dead space in man. J. appl. Physiol. 1959, 14, 339.

8. West, J. B., Fowler, K. T., Hugh-Jones, P., and O'Donnell, T. V. Measurement of the ventilationperfusion ratio inequality in the lung by the analysis of a single expirate. Clin. Sci. 1957, 16, 529.
9. West, J. B., Fowler, K. T., Hugh-Jones, P., and O'Donnell, T. V. The measurement of the inequality of ventilation and of perfusion in the lung by analysis of single expirates. Clin. Sci. 1957, 16, 549.

10. Svanberg, L. Influence of posture on the lung volumes, ventilation and circulation in normals. A spirometric-bronchospirometric investigation. Scand. J. clin. Lab. Invest. 1957, 19, suppl. 25.

11. Lagerlöf, H., Eliasch, H., Werkö, L., and Berglund, E. Orthostatic changes of the pulmonary and peripheral circulation in man. A preliminary report. Scand. J. clin. Lab. Invest. 1951, 3, 85.

12. Mattson, S. B., and Carlens, E. Lobar ventilation and oxygen uptake in man. Influence of body position. J. thorac. Surg. 1955, 30, 676.

13. Forster, R. E., Fowler, W. S., Bates, D. V., and Van Lingen, $B$. The absorption of carbon monoxide by the lungs during breathholding. J. clin. Invest. 1954, 33, 1135.

14. Marks, A., Cugell, D. W., Cadigan, J. B., and Gaensler, E. A. Clinical determination of the diffusion capacity of the lungs. Amer. J. Med. 1957, 22, 51.

15. Mittman, C., and Burrows, B. Uniformity of pulmonary diffusion: Effect of lung volume. J. appl. Physiol. 1959, 14, 496.

16. Marshall, R. A comparison of methods of measuring the diffusing capacity of the lungs for carbon monoxide. Investigation by fractional analysis of the alveolar air. J. clin. Invest. 1958, 37, 394.

17. Filley, G. F., MacIntosh, D. J., and Wright, G. W. Carbon monoxide uptake and pulmonary diffusing capacity in normal subjects at rest and during exercise. J. clin. Invest. 1954, 33, 530.

18. Riley, R. L., and Cournand, A. Analysis of factors affecting partial pressures of oxygen and carbon dioxide in gas and blood of lungs: Theory. J. appl. Physiol. 1951, 4, 77.

19. Forster, R. E. Exchange of gases between alveolar air and pulmonary capillary blood: Pulmonary diffusing capacity. Physiol. Rev. 1957, 37, 391.

20. Burrows, B., and Harper, P. V., Jr. Determination of pulmonary diffusing capacity from carbon monoxide equilibration curves. J. appl. Physiol. 1958, $12,283$.

21. Gilson, J. C., and Hugh-Jones, P. Lung Function in Coalworkers' Pneumoconiosis. London, H. M. Stat. Off., 1955.

22. Krogh, M. Diffusion of gases through lungs of man. J. Physiol. 1915, 49, 271.

23. Ogilvie, C. M., Forster, R. E., Blakemore, W. S., and Morton, J. W. A standardized breath holding technique for the clinical measurement of the diffusing capacity of the lung for carbon monoxide. J. clin. Invest. 1957, 36, 1. 